\title{
GLOBAL JOURNAL OF
}

\section{Community Psychology Practice}

\section{PROMOTING COMMUNITY PRACTICE FOR SOCIAL BENEFIT}

\section{Mental Health Systems Transformation through Participatory Evaluation and Action: The Transition-age Youth Appreciative Inquiry/Photovoice ("YAP") Project}

Thomas M. LaPorte, Mason G. Haber, Damie Jackson-Diop, and Brittany Holt

\section{Author Notes:}

Thomas M. LaPorte, M.A. is a Ph.D. candidate in the Health Psychology program at the University of North Carolina at Charlotte in Charlotte, NC | e-mail: tlaporte@uncc.edu

Dr. Mason G. Haber, Ph.D., is an Assistant Professor in the Psychology Department at the University of North Carolina at Charlotte in Charlotte, NC | e-mail:

mhaber@uncc.edu

Damie Jackson-Diop, M.A., is the Youth Transition Program Director at North Carolina Families United, Inc., NFFCMH, in Burlington, NC | e-mail:

damiejack@ncfamiliesunited.org

Brittany Holt, M.A., is the Youth Program Adviser of YouthMOVE North Carolina in Greensboro, NC | e-mail: blholt87@gmail.com

Acknowledgements: Funding for the YAP project was provided by the North Carolina Division of Mental Health, Developmental Disabilities and Substance Abuse Services. We would like to thank the University of North Carolina at Charlotte undergraduate research assistants contributing to the project, including Mar John Lynch, Jowette Brown-Holmes, April Kinton, and Maritza Ortiz, as well as Gail Cormier, Executive Director of North Carolina Families United, for her guidance and support. Please refer to the online video for the project to see acknowledgements for NC Families United and YouthMOVE participants at: http://www.ncfamiliesunited.org/youthmove/

Keywords: youth, photovoice, mental health, participatory action research, program evaluation

Recommended Citation: LaPorte, T.M., Haber, M.G., Jackson-Diop, D., \& Holt, B. (2014). Mental Health Systems Transformation through Participatory Evaluation and Action: The Transition-age Youth Appreciative Inquiry/ Photovoice ("YAP") Project. Global Journal of Community Psychology Practice, 5(1), 1-12. Retrieved Day/Month/Year, from (http://www.gjcpp.org/). 


\title{
Mental Health Systems Transformation through Participatory Evaluation and Action:
}

\section{The Transition-age Youth Appreciative Inquiry/Photovoice ("YAP") Project}

\begin{abstract}
Participatory action research and evaluation methods (PAR) have been used to help individuals to address a variety of challenges and improve the responsiveness of service systems to these challenges. To the present, however, few studies have examined applications of PAR in systems change advocacy for youth with mental health needs in the transition to adulthood (transitionage youth [TAY]). PAR may be especially beneficial in systems transformation efforts for this population, which lacks resources of other mental health system consumers for advocacy such as formal settings, specialized professional attention, and well established consumer organizations. The present paper describes how specific strategies for PAR, including Appreciative Inquiry and Photovoice, were employed in the Youth Appreciative Inquiry and Photovoice (YAP) project to: 1) gather perspectives of TAY in two statewide youth and family operated programs on needs and aspirations, current responsiveness of their programs and systems, and possible targets for program and system improvement; and 2) share these perspectives with stakeholders to effect change through a video. Findings on these perspectives as well as the impact of video showings are presented, and implications for systems change benefitting TAY and other populations facing systems-level challenges are discussed (191 words).
\end{abstract}

\section{Keywords: youth, photovoice, mental health, participatory action research, program evaluation}

The marginalization of individuals with mental health needs (MHN) across the lifespan is well documented, from children with severe emotional disturbances to adults with severe and persistent mental illnesses (New Freedom Commission on Mental Health, 2003). Community psychologists have sought to empower adult individuals with MHN to overcome marginalization (e.g., Fairweather Lodges, GROW; Seidman, 2012) and developed new systems for children that help families to obtain services and supports that better address their self-identified needs (Cook \& Kilmer, 2012). However, to date, less work has been done to address systems issues of youth with MHN transitioning from child to adult services and settings (e.g., adult mental health, independent living). At present, these transition-age youth (TAY) are poorly served in both child adult systems (Davis, Green, \& Hoffman, 2009).

Efforts to create more responsive programs for transition-age youth have been hampered by lack of understanding and ownership of needs of TAY by child and adult system stakeholders (Davis et al., 2009). Theoretical and methodological tools, including participatory action approaches such as Photovoice (Wang \& Burris, 1997) and the strengths-based organizational development framework, Appreciative Inquiry (Cooperrider \& Srivastva, 1987), are well suited to attempts to empower this neglected constituency. Photovoice methods have been used to assist marginalized populations in increasing awareness and understanding of their challenges, and in so doing, motivate change efforts (Catalani \& Minkler, 2010). Appreciative Inquiry has been used to help groups achieve aspirations for themselves, their organizations, and broader communities by recognizing their existing strengths and resources, and can help critical methods such as photovoice that can be excessively "problemcentric" become more "opportunity-centric" (Boyd \& Bright, 2007). However, although many community psychologists have adopted Photovoice and Appreciative Inquiry approaches separately in various types of PAR work, to date, use of these methodologies in tandem is limited to a handful of very recent examples (e.g., Jackson et al., 2014), and few if any appear in community psychology journals.

This article focuses on a project using PAR as well as Appreciative Inquiry and Photovoice methods with participants in a statewide collaborative effort to transform mental health services for TAY with MHN. The Youth Appreciative Inquiry/Photovoice (YAP) project, involved a university based evaluation team from the University of North Carolina at Charlotte (UNCC), and representatives from two youth- and family-operated support and advocacy organizations, including a young adult consumer group, the North Carolina Chapter of Youth Motivating Others through Voices of Experience (YouthMOVE), and an advocacy group for parents of youth with MHN that also provides services for TAY, North Carolina Families United (NC Families). The paper describes how Appreciative 
Inquiry (AI) and Photovoice were used to: 1) describe needs, strengths and aspirations of young adults, family members, and other stakeholders (evaluation); 2) identify and advocate for use of resources to improve responsiveness of mental health and other community systems to TAY's needs, strengths, and goals (action). Examples of YAP project adaptations of conventional $\mathrm{AI}$ and Photovoice processes are described, including efforts to overcome logistical obstacles and implications for use of Photovoice and other participatory strategies in challenging environments (e.g., the use of an online social network and workspace platform to facilitate participation among those who could not attend in-person meetings). Findings from the project are also described, including themes from photos, photo captions, and interviews, and data on the impact of dissemination of a video documenting the project. Observations are also shared by a youth contributing to the project (the fourth author).

\section{The "Double Burden" of TAY with MHN}

TAY face a "double burden" of marginalization, as they live in a society that often dismisses perspectives of youth as well as stigmatizes MHN (Delman, 2012). They may be in institutional contexts (e.g., mainstream comprehensive high schools) where power imbalances associated with age are especially pronounced (Checkoway \& Richards-Schuster, 2003). Poor responsiveness of mental health and other service systems can compound these common forms of social exclusion. Examples of specific systems issues faced by TAY include lack of access to developmentally appropriate services, discomfort with older adults in adult service systems, service discontinuation or discontinuity due to lack of alignment of child and adult systems, poorly coordinated transitions between child and adult service providers, and discomfort of adult providers in working with families (Davis et al., 2009). Efforts to address mental health symptoms are also often poorly aligned or can even interfere with goals valued by transition-age youth such as obtaining rewarding employment (Jivanjee \& Kruzich, 2011). Collectively, these systems issues are pronounced and complex, involve vested interests that are resistant to change, and are perpetuated by imbalances of power between transition-age youth with MHN, service providers, policy makers, and other gatekeepers of resources (Heflinger et al., 2009). As in other adultyouth partnership projects to reform change-resistant systems for youth (Wong, Zimmerman, \& Parker, 2010), effective PAR could help to persuade gatekeepers in relevant child and adult service systems of the need for change and point to existing strengths of youth, organizations, and systems that can contribute to change.

\section{Implications of Prior Transformation Efforts for Using PAR with TAY}

Many examples of using narrative to drive change are available in the literatures on consumer-driven child and adult mental health system reform (cf. Corrigan, 2004). Adult consumers as well as the families of children receiving mental health services have pushed for (and in some ways achieved) greater responsiveness in their respective systems, in part through sharing narratives that drive advocacy, a general process that is at the heart of PAR methods (Catalani \& Minkler, 2010). Among other achievements, such efforts have propelled the development of a vast array of consumeroperated organizations for adults and families of child consumers (Goldstrom et al., 2006). Thus, although much progress remains to be made (New Freedom Commission on Mental Health, 2003), advocacy efforts driven by personal narratives have accomplished a great deal for a variety of consumer groups.

Recently, it has been argued that services for TAY are at an analogous point in their development to that of child and family services when the movement for systems of care first emerged (Davis et al., 2012). At that time, few if any specialized programs for children existed, and services mostly involved removing youth from their families and placing them in institutions (Stroul \& Friedman, 1986). In response, a child and family behavioral health system emphasizing family and community-based, family driven services was created, toward which youth and family consumer groups have targeted ongoing advocacy in continuing to refine systems for their respective interest groups (Huang et al., 2005). In a similar manner, today, a "transition-age youth mental health system" around which TAY and their families can organize and advocate is lacking, despite the ample evidence that needs of TAY are poorly served both by existing child and adult systems (Davis \& Koroloff, 2006). The adult and child and family systems, operated by and created for adults (i.e., adult consumers, or families of child consumers), may be resistant to youth advocacy efforts because they do not speak "youth language" and provide fewer opportunities for youth to develop social networks with their peers (Delman, 2012). To precipitate efforts to develop their own system and associated advocacy, TAY may need alternative settings in which to develop their own voices, without resistance by existing systems or advocacy groups representing older consumers or families of younger ones.

\section{Helping TAY Pursue Transformative Change through AI and Photovoice}

To provide alternative settings for fostering advocacy, PAR methods, used in a developmentally appropriate 
manner (Wong et al., 2010), clearly show potential. PAR projects, conducted in adult-youth partnerships involving skilled adult facilitators such as community psychologists and emerging peer-based organizations (e.g., YouthMOVE) can provide youth with skills and forums for nurturing their capacities for organizing and advocacy. Emerging peer organizations can provide the basic resources needed for PAR, including physical space, materials (e.g., digital cameras) and the connections to service providers and other adults needed to "get the message out" to those in systems that are well positioned to assist with change. Such a strategy may be particularly promising where peer organizations can garner resources from other types of groups (e.g., family organizations like NC Families).

Although a variety of PAR strategies could be used in advocating for transformative change with TAY, the participatory approaches of Appreciative Inquiry (AI) and Photovoice are especially promising, as they offer complementary theoretical and methodological strengths. Although numerous specific AI methodologies exist, most follow the general "4D" cycle of processes of 1) discovery (of processes already working well), 2) dreaming (of how processes could work well in future), 3) design (of a plan for implementing processes), and 4) destiny (implementation of the plan) (Boyd \& Bright, 2007). Collectively, these frames serve as, in the language of systems of care, a "strengths-based" means for capturing perspectives of stakeholders and generating ideas for change. However, the AI method, originally created to assist with organizational development, can be challenging to implement with some groups, as participants may not be comfortable with verbalizing the abstract concepts associated with appraisal and planning at organizational and systems levels. Photovoice can assist with expression of these complex ideas, providing alternatives to verbal expression in capturing personal experiences and how these relate to systems change ideas (Lorenz \& Kolb, 2009).

Photovoice also provides compelling vehicles for disseminating advocacy messages in a persuasive way. Finally, AI and Photovoice processes align well with promising positive youth development based service models for TAY, such as the Rehabilitation, Empowerment, Natural Supports, Education, and Work model (RENEW; Malloy, Drake, Cloutier, \& Couture, 2011), used by one of the NC Families programs.

AI can complement Photovoice as well. As typically implemented, social action strategies (including Photovoice), may not be a good fit to transitioning adolescents and young adults. In contrast to social action approaches, which are primarily focused on rectifying social injustice and often "problem-centric" (vs. "opportunity-centric; Boyd \& Bright, 2007), TAY tend to be highly optimistic, tend not to see themselves as victims, are self-focused (Arnett, 2000), and prefer contemplating future goals to focusing on "recovering" from challenges (in fact, even, the notion of "recovery" itself, implying existing deficits, may be alienating to TAY; Leavy, 2005). Because AI is explicitly a strategy in which emphasis is placed on envisioning a positive future ("dreaming"), using the AI framework as a source for prompts and frames may help shape social action strategies such as Photovoice to better match the optimistic orientation of TAY. An additional benefit of combining AI with Photovoice is the characteristic use in AI of a peer interviewing approach, rather (as is more typical of Photovoice) interviewing by research personnel. By encouraging greater ownership over the reflection process, peer interviewing has the potential to enhance engagement of youth in Photovoice projects, especially efforts in Photovoice to build momentum for action through reflection, often a failing of projects with youth (Catalini \& Minkler, 2010).

\section{A Brief History of the Project}

The UNCC evaluation team and NC Families first began working together to evaluate their programs for TAY with MHN in late 2009. NC Families offers two programs to support TAY: 1) an intensive case management and mentoring program using the RENEW model, designed to help identify and coordinate resources for supporting transitions to adult roles (e.g., school-to-career transition); 2) a leadership program, the Youth Leadership Series (YLS), the focus of which is helping youth advocate for themselves and peers in their own services and systems change efforts. The YLS is operated in partnership with the North Carolina chapter of YouthMOVE, a national, youth-run advocacy organization affiliated with an organization for families of children with mental health needs, the Federation of Families for Children's Mental Health (FFCMH). NC Families also offers various curricula on supporting transition to adulthood of TAY to youth, parents, and providers.

In the summer of 2012, NC Families and UNCC began discussing possible improvements in the evaluations of NC Families' RENEW and YLS programs. The existing evaluations, consisting of an outcome and fidelity assessment for the RENEW model, and a prepost- satisfaction survey for the YLS, used standard quantitative evaluation methods (e.g., structured rating and self-report instruments). These approaches were found lacking by both NC Families and the UNCC team because they: 1) were not participatory, and 2) did not adequately capture youth's subjective experiences. To address these objectives, UNCC generated the proposal for using AI and Photovoice strategies for PAR that subsequently developed into the YAP project. 
A third objective of the project - advocacy for changes in service systems for TAY, the "action" component of the project - was not identified until shortly before initial YAP project activities were implemented. The addition of this objective occurred largely due to recognition by the NC Families' Transitions Program director (the second author) that concluding meetings for the initial phase of the YAP project were scheduled to occur in May, designated as national Mental Health Awareness month (http://www.whitehouse.gov/thepress-office/2013/04/30/presidential-proclamationnational-mental-health-awareness-month-2013). She proposed, therefore, that initial product(s) of Photovoice activities could be shared in the context of NC Families and YouthMOVE's planned mental health advocacy activities. The decision was made by NC Families and UNCC to produce a video for MHA month as a means of combining and sharing the various forms of data (i.e., interview, photo, and photo caption content) with a variety of audiences.

\section{Method}

\section{Participants \& Recruitment}

TAY were eligible for the YAP project if they had participated in either the RENEW or YLS programs. A variety of means were used to recruit as many participants in these programs as possible, drawing on the expertise of YouthMOVE board members to devise and implement recruitment strategies, including use of the organization's Facebook page (http://www.facebook.com/ncyouthmove) and the social network of YouthMOVE board members to spread word of the project and encourage participation. YouthMOVE board members also helped plan and implement the project in a variety of other ways, and for this reason were referred to as Research Assistants (RAs). For contributing in this special capacity, RAs received compensation of $\$ 50$. Ultimately, ten participants were recruited, ranging in age from 17 and 26. Five participants were YouthMOVE board members and five were regular YouthMOVE members.

\section{Sources and Forms of Qualitative Data}

The prompts were derived from the first three phases of the four-phase AI 4-D cycle (i.e., discovery, dreaming, design, and destiny; Cooperrider \& Whitney, 2005), retaining the developmental orientation of moving from discovery of strengths to envisioning and planning (dreaming and design, respectively; destiny refers to the actual implementation of the plan). Project participants were asked to answer three questions, including two discovery questions (i.e., "What do youth need to be successful adults?" and "In what positive ways have you changed through being in NC Families United's programs?"), and a dreaming and design question
("What would make NC Families United an even better organization?"). Participants answered questions through multiple media, including photography, written-word, and video-recorded interviews. All participants submitted at least one photo and an associated written-caption, and five participants engaged in interviews.

\section{Procedures}

Planning \& introduction of project. Planning for YAP occurred in January and February of 2013. The project design followed AI's strengths-based and developmental orientation (i.e., from focus on needs, to what's working well, to what can be expanded) in the construction of qualitative prompts and in the use of peer-based interviewing in Photovoice activities (i.e., critical reflection on photos). Four sessions were held with youth to facilitate Photovoice activities from February to May of 2013. During Session 1, the project was introduced to the YouthMOVE board and recruitment of additional youth planned. Board members were also introduced to an online platform, Wiggio (Wiggio.com, 2013), for project communications and data collection. In Session 2, the project was introduced to the broader YouthMOVE group (i.e., the 5 participants from the regular membership), and all (board and regular members) were trained in Photovoice methods.

Collection of photos. Photos were collected between Session 2 and Session 4 (median number per youth = 2; range $=1$ to 3 ). Project personnel (i.e., UNCC evaluation team and all YAP participants) conducted much of the photo and caption data-collection via the Wiggio account. The first author also collected photos and captions through text messaging and provided support (e.g., clarified qualitative prompts) through phone calls with all (RAs and regular members) participants. All participants took photos with their own cameras or smartphones and uploaded them to Wiggio or texted them to the lead evaluator. UNCC team members and YouthMOVE RAs also used Wiggio to conduct videoconferences, post documents such as instructions for photography and photos/captions uploading, and provide reminders and words of encouragement.

Online processes $\&$ rationale. Online processes were used for collecting photos and reflections two reasons: 1) for logistical reasons (because project personnel were from various parts of the state); and 2) to complement in person with communications through technology such as text messaging to make the project more engaging. A brief review of the existing literature revealed that online methods such as texting successfully heighten youth interest and participation (cf. Pollock \& Amaechi, 2013). Specific techniques 
were used to maximize the potential of text messaging as an engagement tool. For example, to encourage youth to submit photos, several "challenge of the day" texts were sent, in which specific prompts were used to remind youth of the ongoing Photovoice activities and stimulate fresh reflection.

In-person reflection on photos. The final sessions (Sessions 3 and 4) involved interviews with youth about their Photovoice experiences. After receiving a brief training consisting of reviewing guidelines for interviewing and a practice opportunity, RAs led interviews with one another and with regular (i.e,, nonboard) YouthMOVE members. Interviews included the three questions that were used to prompt photos and captions, with follow-up questions asked as appropriate to provide further clarification or detail.

Development and dissemination of video. The first author led the video-creation process by developing an initial outline with a UNCC film student and the supervising UNCC faculty member. The outline created two sections - one for interviews and one for photos and captions - and included a script for a text-based narrative. The first author organized the interview section by interview question and photo/caption section by qualitative theme. Following this, he made revisions to the ordering of themes and the text-based narrative in consultation with the Transitions Program director and YouthMOVE president (i.e., the fourth author). The video was then edited by the UNCC film student, shared with RAs, and then edited again with RA input. All participants were asked to view the final video and share any thoughts, insights, or suggested revisions.

The final video included an interview portion and a photo/caption portion. In the interview portion, youth $(n=4)$ and parents $(n=2)$ described what they thought youth needed to be successful adults (e.g., positive influences) and ways that they have grown from being involved with NC Families United programs (e.g., "I've become a better mom"). The photo/caption section presented youths' photos organized into themes, such as support, motivation, and college and careers. The video closed with a series of photos and captions highlighting youths' lived experiences (i.e., living with mental health challenges).

RAs presented the video at the following forums during the first week of Mental Health Awareness month (May of 2013): 1) the National Leadership Institute for

Reclaiming Futures

(http://www.reclaimingfutures.org/blog/), a conference on research and policy related to youth involved in the juvenile justice system and substance abuse treatment; 2) North Carolina State Systems of Care (SOC) Collaborative for Children, Youth and Families (http://www.nccollaborative.org/system-of-care/), a group of organizational representatives and other stakeholders, including consumers); and 3) the North Carolina Mental Health Planning Council (http://www.ncdhhs.gov/MHDDSAS/councils/ncmental healthplanningcouncil/index.htm), an advisory board advocating for federal funding for North Carolina.

Assessing video impact. Impact of the video was assessed through a variety of means. In order to ascertain the impact on audience members at presentations of the video, the first author interviewed the second and fourth author, both of whom were present at these events. Additionally, audience feedback at the Reclaiming Futures conference was obtained via conference-issued satisfaction surveys, which included a single item rating the session ( $1=$ poor; $5=$ excellent) and spaces for open-ended comments. NC Families also examined whether interest in their programs increased following presentations of the video during Mental Health Awareness Week by examining changes in activity on their organizational website ("hits") and the frequency of phone calls during Mental Health Awareness Month relative to prior months.

\section{Qualitative Analysis}

Development and validity checking of codes. Photo and caption content was first assembled in a matrix with cells defined by the youth participant and prompt. Qualitative analyses involved initial coding, refinement of these initial codes (i.e., constant comparison method; Bryant \& Charmaz, 2007), and development of code definitions by the first and second authors. Each photo and caption was treated as a single unit (i.e., one code for both) and all photo-caption units were coded. Two RAs (including the fourth author and another YouthMOVE board member) reviewed the codes and provided feedback for further refinement and finalization of coding. Although initial codes were progressively refined through these procedures, no second-order grouping of codes by category or theme occurred, due to the relatively small amount of data collected, and the desire to adhere as closely as possible to the data in interpretation.

Reliability analysis. After codes were developed and refined as indicated above, the first and second authors trained three undergraduate volunteers in coding and reviewed definitions for the set of codes developed by the first and second authors. Following training, undergraduate team members worked as a group, independently of the first and second authors, to assign codes to content. Codes of the first two authors and three undergraduates were then compared to assess their reliability. Only codes for which agreement exceeded $60 \%$ were included in results. For these codes, any cases of disagreement were resolved through discussion prior to summarizing content for each code. 


\section{Results}

\section{Results from Qualitative Coding}

The themes identified included individualized career planning, mentorship, natural support, voice for self and others, responsive systems, and youth resilience and recovery.

Individualized career planning. Individualized career planning (25\% of assigned codes; $40 \%$ of participants) was assigned where youth alluded to working with their program mentors or other supportive adults in developing individual vocational interests, goals, and plans. For example, in response to the question, "in what positive ways have you changed through being in NC Families United", one youth stated "Jobs! Let me know what jobs I love to do... what I like and what I don't like." The associated photo (Figure 1) shows the youth's car, which he bought through saving income earned through a car cleaning business, established while participating in NC Families programs.

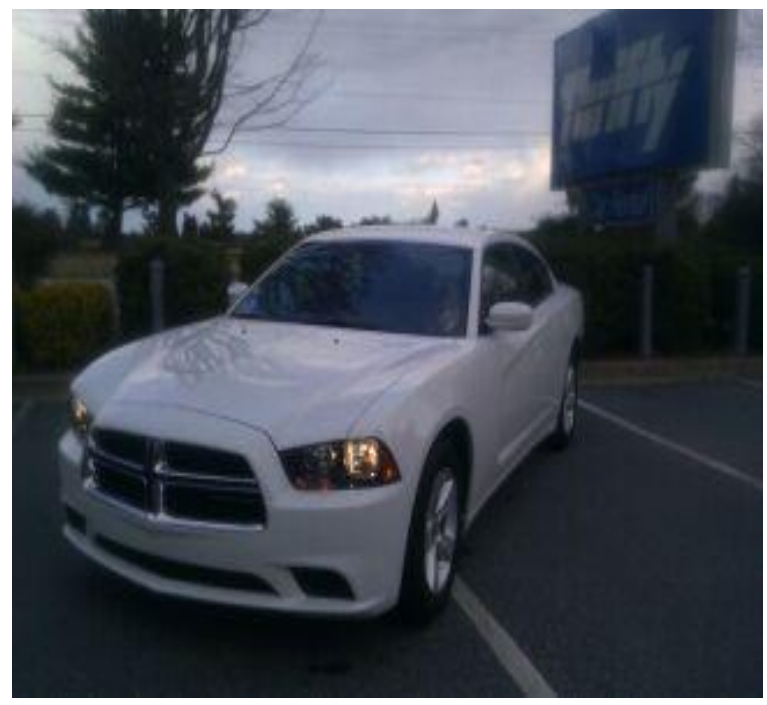

Figure 1. Jobs! Example for Individualized Career Planning theme.

Mentorship. Mentorship (13\% of assigned codes; 33\% of participants) was defined as the experience of working one-on-one with someone who provides support and facilitates self-growth. The following photo caption and the associated picture (in response to the question, "what do youth need to be successful adults?"; Figure 2) was assigned this code:

Youth need someone to show them they can shine, show them how to light up and lead their own path. 
Voice for self $\boldsymbol{\&}$ others. Voice for self and others $(8 \%$ of assigned codes; $20 \%$ of participants) was defined as youth advocacy for improving services for themselves and peers. For example, in response to the question, "What would make NC Families United an even better organization", one youth submitted a photo of a map (Figure 4), with the following caption:

I want to see not only the expansion of NC Families United, but more integration into policy making. We already have some Raleigh members in YouthMOVE, but it'd also be nice to have a chapter out there.

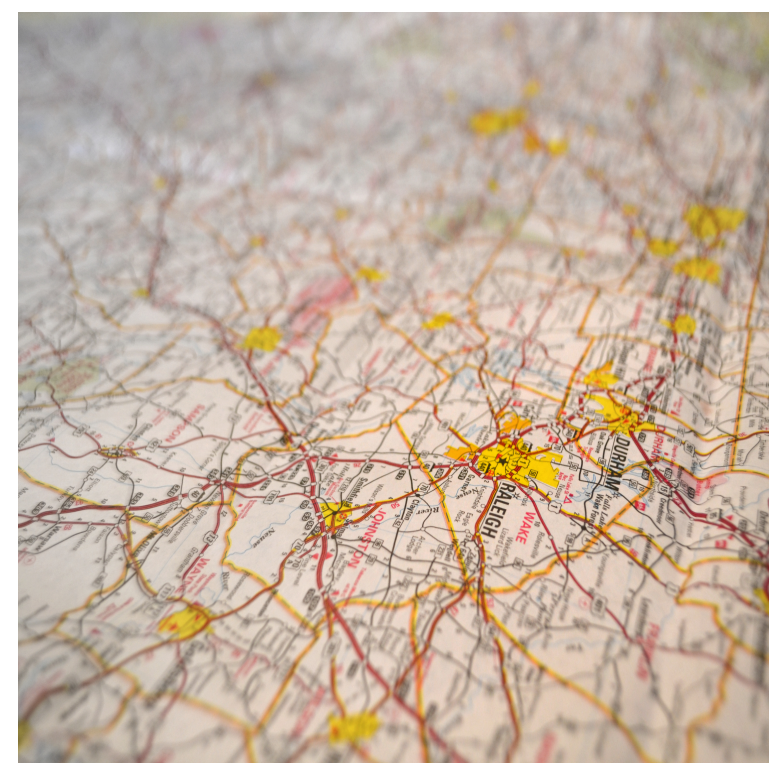

Figure 4. Involvement in policy making. Example for Voice for Self and Others theme.

Youth resilience \& recovery. Youth resilience and recovery (21\% of assigned codes; $33 \%$ of participants) was defined as engagement in activities that promote self-discovery, wellness and healthy transitions to adulthood. It also was assigned to content related to hopes for the future. An example is provided by a photo of a youth jumping on a trampoline with a sunset in the background (Figure 5), accompanied by the following caption:

Nature and I have a lot in common. People judge us, use us, try to destroy us, 'and pollute us all without a care. But we regrow with strength when you cut us, we blossom with beauty...

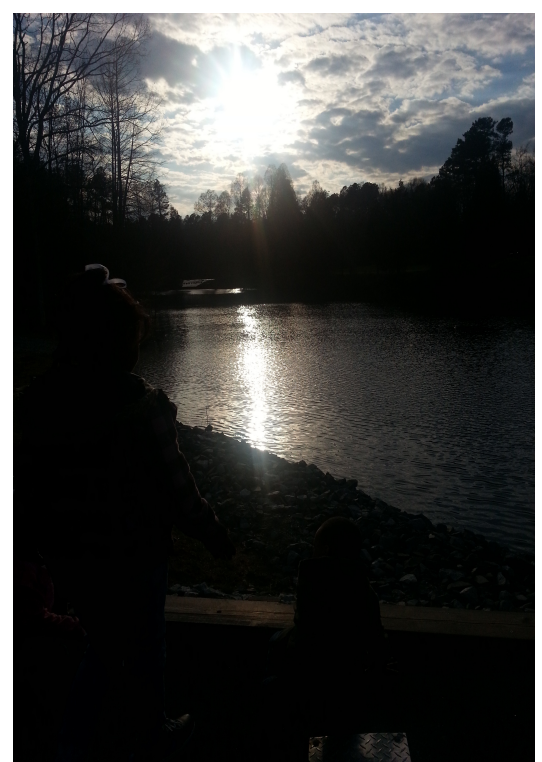

Figure 5. Nature. Example for Youth Resilience and Recovery theme.

Responsive systems. The responsive systems code (17\% of assigned codes; $33 \%$ of participants) referred to descriptions by youth of ways in which systems could better accommodate needs of TAY by: a) being flexible and patient with youth needs, or b) providing opportunities for youth to have experiences helpful for their transition and recovery. The following photo (Figure 6) and caption is an example:

This photo represents a feeling of freedom and light, not feeling held down by stigma and systems that are not helpful.

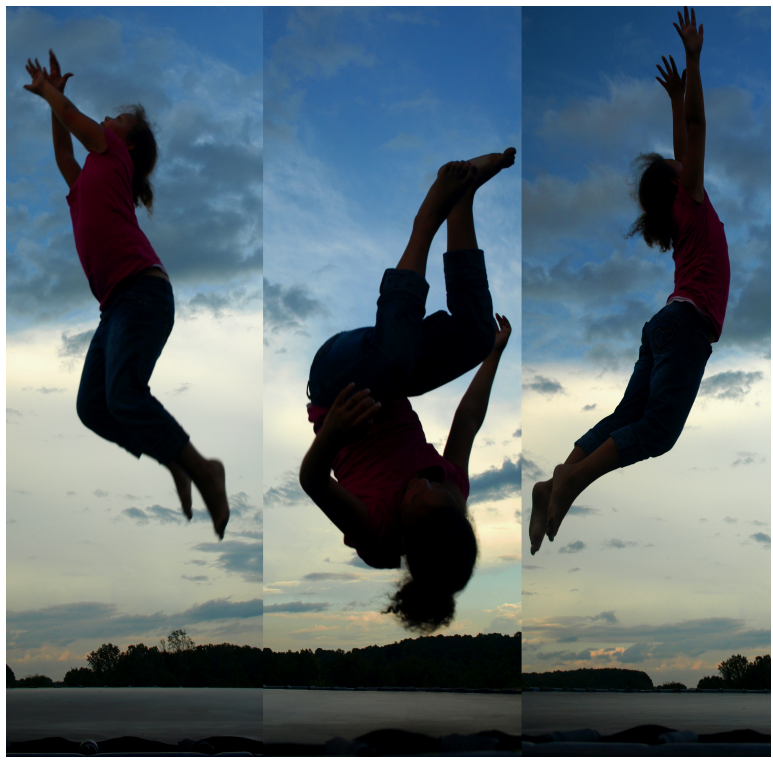

Figure 6. Freedom and Light. Example for Responsive Systems theme. 


\section{Impact of the Video}

Presentations at each of the three venues where the video was shown - the Reclaiming Futures conference, the State Systems of Care Collaborative, and NC Mental Health Planning Council_-were all received quite positively. Following the presentation at the Reclaiming Futures conference, youth presenters received positive feedback from audience members both in-person after their presentation and as indicated on conference surveys. As recounted by the YouthMOVE board member Brittany (the fourth author):

I think the audience members, especially in Ashville at the Reclaiming Futures Conference, were very impacted by the video. We got a standing ovation after the video and our presentation. A lot of people came up to speak to the four of us afterwards. They had to kick us out so the next people could set up. We heard feedback such as, 'thank you so much for doing this'; 'This is great!'; 'We wanna connect with you!'. They were really moved by it.

Mean ratings on satisfaction surveys for the session were 4.67 (i.e., on a five-point scale). Comments contained praise for YouthMOVE and the session (e.g., "powerful" and "moving"). Responses from the State SOC Collaborative were also positive. Following presentation of the video, the Collaborative awarded a $\$ 35,000$ grant to YouthMOVE to help lead program capacity-building and systems change activities, including 1) improving and manualizing the current YLS curriculum, and 2) a statewide assessment of services for TAY. NC MH Planning Council used the video to inform its annual report to the US Department of Health and Human Services.

Following Mental Health Awareness Month activities, NC Families also noted greater interest in their transition programs in a variety of ways, resulting in tangible benefits for the organization. In the month following MHA activities, an $11 \%$ rise in hits on NC Families' webpages for their TAY programs occurred. Phone calls related to TAY programs also increased. For example, several providers called to consult NC Families about establishing services similar to their YLS and RENEW programs. Three contracts to implement YLS in additional communities were obtained. A chief court counselor also called to invite YouthMOVE members to present to judges about their experiences. Overall, NC Families United Executive Director and Board of Directors saw the video as generating considerable awareness of services and helping them to broaden their reach to new communities.
Presenting the video in various forums also appeared to positively impact the YouthMOVE members. Brittany, the fourth author, provided the following observations in this regard:

Our participants really enjoyed the opportunity to speak and to share their experiences....I think the experience of presenting was part of the process. It was like RENEW, where participants are presenting their service goals and experiences to other support people, but that process itself is not just for their supports, but also for them... Being able to say that you attended a conference or overcome your fears by standing in front of people is a valuable experience.

\section{Discussion}

The initial phase of the YAP project described in the present paper provides illustrations of how the participatory and social action strategies of AI and Photovoice can be successfully used by agencies serving transition-age youth with MHN to enhance or complement existing program evaluation and advocacy efforts, in the process strengthening the voice, influence, and well-being of participating youth. With adaptations involving creative use of technology, including uses of the Wiggio platform and text messaging, these strategies proved feasible despite logistical barriers to regular, in person meetings (foremost among these being the wide geographic dispersion of participants). In fact, anecdotally, it appeared that use of Wiggio and text message based communication, beyond simply making project feasible, had a positive impact on youth enthusiasm for and contributions to YAP. Although data are preliminary on the impact of project on resources for TAY in NC service systems and communities, a variety of indicators suggested that some meaningful benefits were rapidly obtained, including increased interest in and commitment of resources toward establishing programs for TAY. These findings were surprising given the limited resources invested in the project.

\section{Program, Youth, \& other Stakeholder Benefits of YAP}

A number of potential benefits of YAP for NC Families' programs for TAY and program stakeholders (including youth) were suggested by findings. These included greater understanding of youth's experiences and aspirations by agency and university evaluation team staff as well as the audiences across the state seeing the project video, many of whom were in positions to effect change (e.g., members of community and state level inter-organizational collaboratives). Qualitative findings (e.g., codes including voice for self and others, youth resilience \& recovery, and responsive 
systems) suggested that TAY saw themselves as benefitting from their participation in a variety of ways, at individual, peer group, and systems levels.

Qualitative data also showed promise as means of informing program evaluation and planning in a manner consistent with the Appreciative Inquiry framework. Youth responses to questions regarding what they thought "youth needed to be successful adults" or "what positive ways have you changed through being in NC Families United" were easily linked to NC Families programming for TAY, particularly the RENEW model program, (e.g., content assigned the individualized career planning, mentorship, and natural support codes). More specific aspects of these programs most valued by youth can be investigated in future Photovoice iterations (e.g., through probes regarding relationships with program mentors and types of statements or actions by mentors that are most helpful to youth). This information, in turn, can be used to enhance the evaluation. For example, self-report probes, observational rating criteria, etc. can be incorporated to assess strategies and specific features of high quality implementation from perspectives of youth. Data can also be used to inform program planning (e.g., the suggestion by a participant of establishing a YouthMOVE chapter in Raleigh to better influence policymaking).

\section{Potential Benefits of the YAP Approach for Systems Transformation}

PAR projects employed within peer and advocacy organizations using the combined AI and Photovoice approach adopted by YAP can contribute to systems transformation in two primary ways. First, products of these activities such as the video help demonstrate the limitations of conventional services and value of emerging, innovative programs. In their photos, captions, and interviews, rather than highlighting service features or goals characteristic of traditional mental health services (e.g., medication or psychotherapy), youth focused on support in their natural environments (e.g., friends, mentors) or programs that focus on school-to-career transitions and developing natural support networks (e.g., RENEW). Making such points through first hand experiences and perspectives is often more compelling than through quantitative findings, as illustrated by past systems transformation efforts (New Freedom Commission, 2003). As a result, emerging, innovative programs may receive increased funding priority, making them more available. As part of such increased emphasis on "youth-driven" programs, the capacity of peer run organizations for youth may also be improved (Corrigan, 2004).
Second, YAP verbal and photographic products demonstrated and - through articulation, reflection, and sharing - likely reinforced an ongoing process of conscientization to issues at the systems levels (cf. Friere, 1970). Although youth perspectives more clearly highlighted "bottom up" approaches to systems transformation (establishing innovative programs and peer run organizations for the population), recognition of needs to address systems level barriers was clear in the codes of voice for self and others and responsive systems and the specific contents to which they were assigned (e.g., one participant even mentioned the desire to develop a YouthMOVE chapter in Raleigh).

\section{Use of AI and Photovoice as Dual PAR strategies with TAY}

TAY with MHC face a number of challenges that social action strategies such as Photovoice can address. The AI adaptation of Photovoice used in the YAP project may enhance Photovoice's suitability for TAY, because it facilitates recognition of strengths and creates a positive vision for change, two strategies that are well aligned with the optimism characteristic of developmental phase of the transition to adulthood (Arnett, 2000). Additionally, rather than having yet another adult ask youth to reflect on their service experiences or past frustrations, the use of peer interviewing (a convention in AI) in the YAP project may also have enhanced the fit of the project design to needs of the population and partnering organizations. As a consequence, YAP participants may have felt greater ownership over the process, which in turn may have enhanced their contributions to dissemination and advocacy efforts using a project product (i.e., the video). Use of peer interviewing was also particularly suited for a peer support and advocacy organization such as YouthMOVE as they embody the spirit of ownership over processes typically owned and operated by professionals. Other such agencies working with youth should consider the potential for social change efforts provided by pairing Photovoice and AI approaches.

\section{Limitations \& Future Directions}

The present paper focuses on initial phases of a timelimited project with a small organization involving relatively few youth and thus, findings cannot be readily generalized to other organizations or localities. Data on impact could be improved through use of more intentional and rigorous measures (e.g., satisfaction and perceived impact measures designed for the project, more systematic and complete assessments of fluctuations in statewide interest in programs for TAY). There may also be limits to the use of findings from AI and Photovoice methods conducted with groups that have lived experience but lack specialized knowledge 
to inform complex decisions related to program planning or advocacy. For youth to meaningfully contribute to these decisions, they (or representative leaders) may need to be assisted in developing the technical skills needed for analysis and persuasive communication related to policymaking. Development of such competencies is an important contribution of organizations such as YouthMOVE, and community psychologists certainly can contribute to training members of such organizations to participate in skilled evaluation, advocacy roles.

Much work remains to be done to use YAP project findings to help shape NC Families and YouthMOVE programs and program evaluations. Future activities planned for the YAP project include further showings of the YAP video and collection of data on impact from additional audiences (e.g., showings at a conference on children's mental health research and policy).

Additional Photovoice sessions, focus groups, and interviews are also planned to more comprehensively capture views of NC Families and YouthMOVE youth, as well as views of parents and other family. Following this additional data collection, findings for the completed project will be presented to the NC Families United and YouthMOVE boards and used to inform strategic planning of their services and advocacy activities by their organizations.

\section{Conclusion}

As illustrated by compelling images contributed by youth participants in the YAP project, TAY with MHNs and their families can "regrow with strength", and "blossom with beauty" in response to their current marginalization in mental health and other service systems. Community psychologists can apply the complementary methods of AI and Photovoice to help TAY to this end, using personal narrative to provoke critical reflection in themselves and others, and obtain the supports that they deserve to achieve their aspirations and lead productive, fulfilling lives.

\section{References}

Arnett, J. J. (2000). Emerging adulthood: A theory of development from the late teens through the twenties. American psychologist, 55(5), 469. doi: 10.1037//0003-066X.55.5.469

Boyd, N. M., \& Bright, D. S. (2007). Appreciative Inquiry as a mode of action research for community psychology. Journal of Community Psychology, 35, 1019-1036. doi:10.1002/jcop.20208

Bryant, A., \& Charmaz, K. (Eds.). (2007). The Sage handbook of grounded theory. Sage.

Research. American Journal of Evaluation, 24(1), 2133. doi:10.1016/S1098-2140(02)00268-0
Catalani, C., \&, M. Minkler. (2010). Photovoice: A review of the literature in health and public health. Health Education \& Behavior, 37, 424-451. doi:10.1177/1090198109342084

Checkoway, B., \& Richards-Schuster, K. (2003). Youth Participation in Community Evaluation

Cook, J. R., \& Kilmer, R. P. (2012). Systems of care: New partnerships for community psychology. American Journal of Community Psychology, 49, 393-403. doi:10.1007/s10464-012-9516-8

Cooperrider, D. L., \& Srivastva, S. (1987). Appreciative Inquiry in organizational life. Research in Organizational Change and Development, 1, 129-169.

Cooperrider, D., \& Whitney, D. D. (2005). Appreciative inquiry: A positive revolution in change. BerrettKoehler Publishers.

Corrigan, P. (2004). How stigma interferes with mental health care. American Psychologist, 59(7), 614-625. doi:10.1037/0003-066X.59.7.61

Davis, M., Green, M., \& Hoffman, C. (2009). The service system obstacle course for transition-age youth and young adults. In Clark, H.B. \& Unruh, D.K. (Eds.), Transition of youth \& young adults with emotional or behavioral difficulties (pp. 25-46). Baltimore: Brookes.

Davis, M., \& Koroloff, N. (2006). The great divide: How public mental health policy fails young adults. In W.H. Fisher (Ed.), Community-based mental health services for children and adolescents (Vol. 4, pp. 53-74). Oxford, UK: Elsevier.

Davis, M., Koroloff, N., \& Ellison, M. (2012). Between adolescence and adulthood: Rehabilitation research to improve services for youth and young adults. Psychiatric Rehabilitation Journal, 35(3), 167-170. doi:10.2975/35.3.2012.167.170

Delman, J. (2012). Participatory Action Research and young adults with psychiatric disabilities. Psychiatric Rehabilitation Journal, 35(3), 231-234. doi:10.2975/35.3.2012.231.234

Freire, P. (1970) Pedagogy of the Oppressed. New York: Continuum.

Goldstrom, I. D., Campbell, J., Rogers, J. A., Lambert, D. B., Blacklow, B., Henderson, M. J., \& Manderscheid, R. W. (2006). National estimates for mental health mutual support groups, self-help organizations, and consumer-operated services. Administration and Policy in Mental Health, 33, 92103. doi:10.1007/s10488-005-0019-x 
Huang, L., Stroul, B., Friedman, R., Mrazek, P., Friesen, B., Pires, S., \& Mayberg, S. (2005). Transforming mental health care for children and their families. American Psychologist, 60, 615-627. doi:10.1037/0003-066X.60.6.615

Jackson, F., Saran, A. R., Ricks, S., Essien, J., Klein, K., Roberts, D., \& Worthy, N. (2014). Save 100 babies $($ : : Engaging communities for just and equitable birth outcomes through Photovoice and Appreciative Inquiry. Maternal And Child Health Journal. Advance online publication. doi:10.1007/s10995-014-1436-9

Jivanjee, P., \& Kruzich, J. (2011). Supports for young people with mental health conditions and their families in the transition years: Youth and family voices. Best Practices in Mental Health: An International Journal, 7(1), 115-133.

Leavey, J. E. (2005). Youth experiences of living with mental health problems: Emergence, loss, adaptation and recovery (ELAR). Canadian Journal of Community Mental Health, 24(2), 109-126.

Lorenz, L. S., \& Kolb, B. (2009). Involving the public through participatory visual research methods. Health Expectations: An international journal of public participation in health care \& health policy, 12, 262-274. doi:10.1111/j.1369-7625.2009.00560.x

Malloy, J. M., Drake, J., Cloutier, H., \& Couture, D. (2011). RENEW: a secondary transition model for youth and young adults. Institute on Disability, University of New Hampshire.

New Freedom Commission on Mental Health (2003). Achieving the Promise: Transforming Mental Health Care in America. DHHS Pub. No. SMA-033832. Rockville, MD. Retrieved from: http://govinfo.library.unt.edu/mentalhealthcommissi on/reports/FinalReport/.htm

Pollock, M., \& Amaechi, U. (2013). Texting as a channel for personalized youth support: Participatory design research by city youth and teachers. Learning, Media And Technology, 38, 128-144. doi:10.1080/17439884.2013.756516

Seidman, E. (2012). An emerging action science of social settings. American Journal of Community Psychology, 50, 1-16.

Stroul, B. A., \& Friedman, R. M. (Eds.) (1986). A system of care for seriously emotionally disturbed children and youth. Washington, DC: Georgetown University. Retrieved from: https://www.ncjrs.gov/pdffiles 1/Digitization/125 081NCJRS.pdf
Wang, C., \& Burris, M. A. (1997). Photovoice: Concept, methodology, and use for participatory needs assessment. Health education \& behavior, 24, 369-387.

Wong, N. T., Zimmerman, M. A., \& Parker, E. A. (2010). A typology of youth participation and empowerment for child and adolescent health promotion. American Journal of Community Psychology, 46(1-2), 100-114. doi:10.1007/s10464010-9330-0 